\title{
The role of GSK3 and its reversal with GSK3 antagonism in everolimus resistance
}

\author{
Elke Tatjana Aristizabal Prada', Gerald Spöttl', Julian Maurer', Michael Lauseker², Eva Jolanthe Koziolek ${ }^{3,4,5}$, \\ Jörg Schrader6, Ashley Grossman7,8, Karel Pacak ${ }^{9}$, Felix Beuschlein ${ }^{1,10}$, Christoph Joseph Auernhammer ${ }^{1}$ and \\ Svenja Nölting'
}

\author{
'Medizinische Klinik und Poliklinik IV, Interdisciplinary Center of Neuroendocrine Tumors of the GastroEnteroPancreatic System (GEPNET-KUM), Klinikum \\ der Universität München (KUM), Ludwig-Maximilians-University, Munich, Germany \\ 2Institute for Medical Information Sciences, Biometry, and Epidemiology, Campus Grosshadern, Ludwig-Maximilians-University of Munich, \\ Munich, Germany \\ 3Department of Nuclear Medicine, University Medical Center Charité, Berlin, Germany \\ ${ }^{4}$ German Cancer Consortium (DKTK), Heidelberg, Germany \\ ${ }^{5}$ German Cancer Research Center (DKFZ), Heidelberg, Germany \\ ๆ. Medizinische Klinik und Poliklinik, Universitätsklinikum Hamburg-Eppendorf, Hamburg, Germany \\ 7Oxford Centre for Diabetes, Endocrinology and Metabolism, University of Oxford, Oxford, UK \\ 8Royal Free Hospital ENETS Centre of Excellence, London, UK \\ ${ }^{9}$ Eunice Kennedy Shriver National Institute of Child Health and Human Development, National Institutes of Health, Bethesda, Maryland, USA \\ ${ }^{10} \mathrm{Klinik}$ für Endokrinologie, Diabetologie und Klinische Ernährung, Universitätsspital Zürich, Zurich, Switzerland
}

Correspondence should be addressed to S Nölting: svenja.noelting@med.uni-muenchen.de

\begin{abstract}
Pancreatic neuroendocrine tumors (panNETs) are often inoperable at diagnosis. The mTORC1 inhibitor everolimus has been approved for the treatment of advanced NETs. However, the regular development of resistance to everolimus limits its clinical efficacy. We established two independent everolimus-resistant panNET (BON1) cell lines (BON1 RR1, BON1 RR2) to find potential mechanisms of resistance. After 24 weeks of permanent exposure to $10 \mathrm{nM}$ everolimus, BON1 RR1 and BON1 RR2 showed stable resistance with cellular survival rates of $96.70 \%\left(\mathrm{IC}_{50}=5200 \mathrm{nM}\right)$ and $92.30 \%\left(\mathrm{IC}_{50}=2500 \mathrm{nM}\right)$, respectively. The control cell line showed sensitivity to $10 \mathrm{nM}$ everolimus with cellular survival declining to $54.70 \%\left(\mathrm{IC}_{50}=34 \mathrm{nM}\right)$. Both resistant cell lines did not regain sensitivity over time and showed persistent stable resistance after a drug holiday of 13 weeks. The mechanisms of resistance in our cell line model included morphological adaptations, G1 cell cycle arrest associated with reduced CDK1(cdc2) expression and decreased autophagy. Cellular migration potential was increased and indirectly linked to c-Met activation. GSK3 was over-activated in association with reduced baseline IRS-1 protein levels. Specific GSK3 inhibition strongly decreased BON1 RR1/RR2 cell survival. The combination of everolimus with the PI3K $\alpha$ inhibitor BYL719 re-established everolimus sensitivity through GSK3 inhibition and restoration of autophagy. We suggest that GSK3 over-activation combined with decreased baseline IRS-1 protein levels and decreased autophagy may be a crucial feature of everolimus resistance, and hence, a possible therapeutic target.
\end{abstract}

\author{
Key Words \\ - panNETs \\ - stable everolimus resistance \\ - GSK3 \\ - combination treatment
}

Endocrine-Related Cancer (2018) 25, 893-908 


\section{Introduction}

Pancreatic neuroendocrine tumors (panNETs) are a type of gastroenteropancreatic neuroendocrine tumor (GEP-NETs) (Yao et al. 2008). Due to their slow and frequently asymptomatic growth, panNETs are often advanced when diagnosed, such that curative surgery is no longer an option (Briest \& Grabowski 2014). For this reason, the 10 -year survival for panNETs is only $44 \%$, in spite of various advances in treatment modalities (Ekeblad et al. 2008, Halfdanarson et al. 2008, Auernhammer et al. 2017, Aristizabal Prada \& Auernhammer 2018). Common treatments for advanced disease such as biotherapy, chemotherapy, molecular-targeted therapy and peptide radioreceptor therapy remain limited in their efficacy, and novel treatment options are urgently needed (Frilling et al. 2014, Auernhammer et al. 2017, Aristizabal Prada \& Auernhammer 2018).

One of the most important receptor tyrosine kinase (RTK)-induced oncogenic signaling cascades in GEP-NETs is the mTORC1-p70S6K signaling pathway, which can be inhibited by the mTORC1 inhibitor everolimus (Fig. 1) (Zaytseva et al. 2012, Wolin 2013, Shipkova et al. 2016).

Inhibition of mTORC1/p70S6K leads to disinhibition/activation of IRS-1 and, thus, to PI3K/Akt activation

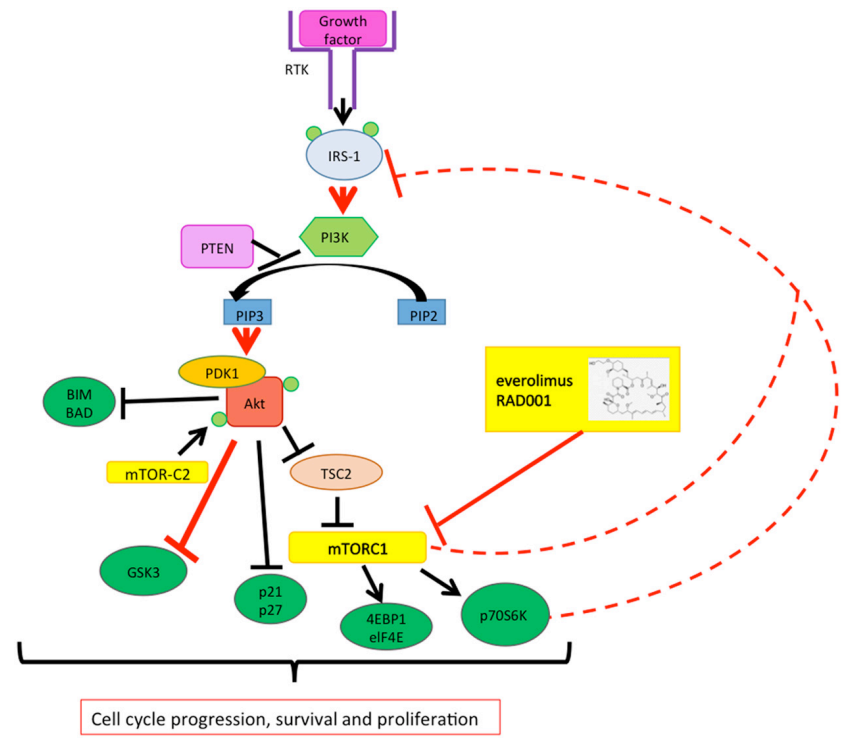

Figure 1

Proposed mechanism of action of the mTORC1-inhibitor everolimus. Everolimus inhibits the mTORC1 complex and thereby down-regulates the mTORC1/p70S6K signaling cascade, preventing the cell from cell cycle progression, survival and proliferation. Inhibition of mTORC1/p70S6K leads to disinhibition/activation of IRS-1 and thereby activation of $\mathrm{PI} 3 \mathrm{~K} / \mathrm{Akt}$, which in turn inhibits GSK3 by phosphorylation. A full colour version of this figure is available at https://doi.org/10.1530/ERC-18-0159.
The PI3K-Akt-mTORC1 axis is frequently over-activated in cancers, including panNETs, causing increased cellular survival, proliferation and protein synthesis (Briest \& Grabowski 2014, Pavel \& Sers 2016). Accordingly, the mTORC1 inhibitor everolimus has shown anti-tumor potential in several clinical phase 3 trials in patients with NETs (RADIANT-2, RADIANT-3, RADIANT-4) (Pavel et al. 2011, Yao et al. 2011, 2016a,b), and has been approved for the treatment of pancreatic, intestinal and pulmonary NETs in many countries (Pavel \& Sers 2016, Chan et al. 2017). Unfortunately, only around 5\% of patients show partial remission in response to everolimus treatment, although many more patients show stable disease. However, most tumors eventually start to progress even if everolimus treatment is continued (Yao et al. 2011). Thus, secondary resistance seems to occur in most patients, although primary resistance may also be a problem (Wagle et al. 2014, Capozzi et al. 2015, He et al. 2016, Vandamme et al. 2016, Zatelli et al. 2016). Advanced panNET patients are treated with a fixed dose of $10 \mathrm{mg}$ everolimus daily (NCT00510068) (Yao et al. 2013, 2014): the majority develops treatment resistance within 1 year of treatment (Capurso et al. 2012, Yao et al. 2013). Consequently, reversible adaptive resistance to everolimus in panNET cell lines, and combinatory regimes to overcome acquired resistance, have been the object of previous studies (Zitzmann et al. 2010, Passacantilli et al. 2014, Vandamme et al. 2016). However, long-term resistance to everolimus treatment has only been little studied to date (Capurso et al. 2012, Passacantilli et al. 2014, Vandamme et al. 2016), and thus, there is an unmet need to better understand the mechanisms of resistance and to establish predictive biomarkers for resistance to everolimus, and hence, appropriate treatments. Activation of autophagy by mTORC1 inhibitors has been reported as one potential mechanism for developing mTORC1 inhibitor resistance and for promoting tumor cell growth (Avniel-Polak et al. 2016, Avniel et al. 2018). Autophagy seems to play a controversial role in cancer: on the one hand, autophagy might offer a protective mechanism in some cancer cells promoting acquired drug resistance (Sui et al. 2013, AvnielPolak et al. 2016). On the other hand, autophagy might also induce autophagic cell death, separate from apoptosis (Sui et al. 2013).

Novel insights into the mechanisms of resistance in response to everolimus treatment could provide a rationale for dual-targeting approaches in order to overcome such acquired or intrinsic resistance (Capurso et al. 2012, Passacantilli et al. 2014, Capozzi et al. 2015, Vandamme et al. 2016, Avniel et al. 2018). Although the study group around Vandamme et al. treated BON1 and 
QGP1 cell lines over 24 weeks with increasing doses of everolimus up to $1 \mu \mathrm{M}$ according to the 'pulse selection model' (McDermott et al. 2014), BON1 and QGP1 cells only showed reversible resistance and regained sensitivity to everolimus after a drug holiday of 10-12 weeks (Vandamme et al. 2016).

Therefore, our aim was to establish a clinically relevant panNET cell line model from BON1 cells, demonstrating stable, that is, consistent and reliable resistance to everolimus in order to study the mechanisms of longterm resistance and explore novel combinatory treatment options to overcome such resistance.

Besides exploring PI3K-Akt signaling as a potential pathway of resistance (O'Reilly et al. 2006, Zitzmann et al . 2010, Passacantilli et al. 2014, Vandamme et al. 2016), we also investigated GSK3 signaling. GSK3 $\alpha / \beta$ is a direct effector protein of Akt: activated Akt phosphorylates and inhibits GSK3 $\alpha / \beta$ (Porta et al. 2014). GSK3 has been implicated in metabolism since GSK3 is inactivated by insulin leading to disinhibition/activation of glycogen synthase. Moreover, it seems to play a role in diseases such as diabetes, Alzheimer's disease and psychiatric diseases, including bipolar disorder and schizophrenia (Maurer et al. 2014). GSK3 $\alpha / \beta$ has shown controversial effects on cell death and survival, including pro- and anti-apoptotic effects (Maurer et al. 2014). Activated GSK $\beta$ has also been reported to target cell cycle proteins such as Cyclin D for degradation (Maurer et al. 2014). On the one hand, treatment with different GSK3 inhibitors (CHIR99021, 6-bromoindirubin-3'oxime-, 1-azakenpaullone) and siRNA stimulated proliferation of rat insulinoma INS-1E cells (Mussmann et al. 2007). Conversely, the nonspecific GSK3 $\alpha / \beta$ inhibitor lithium chloride inhibited neuroendocrine tumor growth in vitro and in vivo (Greenblatt et al. 2010, Lubner et al. 2011); however, in a clinical phase 2 study with 15 patients with low-grade NETs (8 carcinoid tumors, 5 islet cell tumors), the nonspecific GSK3 $\alpha / \beta$ inhibitor lithium chloride caused no objective responses, and pre- and post-treatment tumor biopsies showed no consistent GSK3 $\beta$ inhibitory effects due to insufficient phosphorylation of GSK3 $\beta$ in patients' serum levels (Lubner et al. 2011). To assess the effects of more specific GSK3 $\alpha / \beta$ inhibition on NETs, we have recently investigated the selective GSK3 $\alpha / \beta$ inhibitor AR-A014418 in pancreatic, pulmonary and midgut NET cells and reported a significant inhibitory effect on cell viability and strong GSK3 $\alpha / \beta$ phosphorylation/inhibition (Aristizabal Prada et al. 2017). Biochemical studies have focused on GSK3 $\beta$ inhibition, while other studies have also shown the importance of GSK3 $\alpha$ in drug resistance
(McCubrey et al. 2014). Thus, GSK3 appears to play a pleiotropic role in regulating cell proliferation.

We have used our everolimus-resistant cell line model to demonstrate combinatorial treatments that reversed everolimus resistance via GSK3 inhibition in vitro. In due course, other cell lines can be studied to explore whether they also develop stable resistance and to compare the intrinsic mechanisms. In a pilot study, we transferred our everolimus-resistant cell line model to an orthotopic intrapancreatic xenograft mouse model providing the basis for translating the in vitro approach to an in vivo situation.

\section{Materials and methods}

\section{Cell culture}

The human panNET cell line BON1 (Evers et al. 1991) was kindly obtained from Prof. R Göke (Marburg, Germany). The BON1 cell line was analyzed and certified by the German Biological Resource Centre DSMZ (DSMZ, Braunschweig, Germany) using short tandem repeats (STRs). BON1 cells were grown in DMEM/F12 (1:1) (Life Technologies), supplemented with 10\% FBS (Biochrom, Berlin, Germany), 1\% penicillin/streptomycin (Life Technologies) and $0.4 \%$ amphotericin B (Biochrom) at $5 \% \mathrm{CO} 2$ and $37^{\circ} \mathrm{C}$ and tested mycoplasma-free for all experiments reported. BON1 is a permanent cell line derived from a lymph node metastasis of a human carcinoid tumor of the pancreas and presents phenotypic NET characteristics (Grozinsky-Glasberg et al. 2012).

\section{Experimental design}

In order to yield everolimus resistance in panNET cells, BON1 cells (passage 13) were treated continuously with a constant low dose of $10 \mathrm{nM}$ everolimus for 24 weeks. A dose of $10 \mathrm{nM}$ everolimus was chosen since the plasma levels of everolimus in patients on daily therapy with $10 \mathrm{mg}$ everolimus range between around $8 \mathrm{nM}\left(C_{\min }\right.$ after 2 weeks of daily exposure to $10 \mathrm{mg}$ everolimus) and $59 \mathrm{nM}\left(C_{2 \mathrm{~h}}\right.$ after 12 weeks of daily exposure to $10 \mathrm{mg}$ everolimus) (Budde et al. 2016). Every 3-day medium was exchanged and everolimus treatment was renewed. The concentrations were not increased over time. To determine commonalities in resistance mechanisms in BON1 cells, we have established two independent everolimus-resistant BON1 cell lines (BON1 RR1 and BON1 RR2) in parallel and a control cell line (BON1 Control DMSO) to control for adaptive strategies of long-term in vitro culturing and passaging as such. BON1 is the initial parental cell 
line, from which the development of resistance started. To obtain a sensitive control cell line (BON1 Control DMSO), BON1 was continuously vehicle treated with a comparable concentration of DMSO (0.00005\%) over 24 weeks. We compare our results to the BON1 Control DMSO cell line. In order to assess the stability and reliability of the acquired resistance phenotype, all cells were frozen in liquid nitrogen (minimum for $48 \mathrm{~h}$ ) and thawed, followed by drug withdrawal (McDermott et al. 2014). Resistance was defined as at least a doubling of the $\mathrm{IC}_{50}$, compared to the sensitive control cell line (BON1 Control DMSO), after treatment with $10 \mathrm{nM}$ everolimus for $144 \mathrm{~h}$ (McDermott et al. 2014).

\section{Inhibitors}

The mTORC1 inhibitor everolimus (RAD001), the GSK3 inhibitor AR-A014418 and the PI3K inhibitor BYL719 were acquired from Sigma-Aldrich. All substances were dissolved in dimethyl-sulfoxide (DMSO, Sigma-Aldrich) and stored at $-20^{\circ} \mathrm{C}$. The stock solutions of everolimus, AR-A014418 and Byl719, were $20 \mathrm{mM}$ in DMSO.

\section{Cell viability assessment}

BON1 cells were seeded at $\sim 1500$ cells/96-well for $24 \mathrm{~h}$ in complete medium. Then, the cells were treated with different concentrations of everolimus (from $1 \mathrm{nM}$ to $2 \mu \mathrm{M}$ ), BYL719 (from $1 \mu \mathrm{M}$ to $10 \mu \mathrm{M}$ ) or AR-A014418 (from $5 \mu \mathrm{M}$ to $20 \mu \mathrm{M}$ ) alone or they were treated with everolimus (from $1 \mathrm{nM}$ to $10 \mathrm{nM}$ ) in combination with BYL719 (from $1 \mu \mathrm{M}$ to $10 \mu \mathrm{M}$ ) or in combination with AR-A014418 (from $5 \mu \mathrm{M}$ to $20 \mu \mathrm{M}$ ). The BYL719 concentrations we chose are potentially clinicially relevant since in a clinical study assessing population pharmacokinetics and pharmacodynamics of BYL719 in patients with advanced solid malignancies median BYL719 plasma concentrations between $2 \mu \mathrm{M}$ and $11 \mu \mathrm{M}$ have been found with 1-month daily oral therapy with therapeutically relevant doses of $300-450 \mathrm{mg}$ BYL719 $2-8 \mathrm{~h}$ post dose (De Buck et al. 2014). For everolimus alone, the two final DMSO controls were equal to $1 \mu \mathrm{M}$ everolimus $(0.005 \%$ DMSO final concentration) and $2 \mu \mathrm{M}$ everolimus $(0.01 \%$ DMSO final concentration), respectively, depending on the experiment. For the higher dose BYL719/everolimus combination treatment, the final DMSO control was equal to 1:2000 (Byl719) $+1: 2,000,000$ (everolimus $)=0.05005 \%$ final DMSO concentration. For the lower dose BYL719/everolimus combination treatment, the final DMSO control was equal to 1:4000 (Byl719) +1:2,000,000 (everolimus) $=0.02505 \%$ final DMSO concentration . For AR-A014418/everolimus combination treatment, the final DMSO control was equal to $1: 1000$ $($ AR-A014418) $+1: 2,000,000$ (everolimus $)=0.10005 \%$ final DMSO concentration. The final DMSO concentrations were never higher than $0.1 \%$ and had no significant effect on cell viability. The metabolic activity of living cells was assessed by the 'Cell Titer Blue' cell viability assay (Promega) after $72 \mathrm{~h}$ and $144 \mathrm{~h}$ of incubation with the different agents. Cells were incubated for $4 \mathrm{~h}$ with 'Cell Titer Blue' solution and fluorescence was measured at 560/590 nm using a GLOMAX plate reader (Promega).

\section{Cell cycle analysis by flow cytometric analysis}

Cell cycle phase distribution was analyzed (Riccardi \& Nicoletti 2006) (BD Accuri C6 Analysis). First, cells were cultured in six-well plates for $24 \mathrm{~h}$, before medium was replaced by antibiotic-free medium and incubated with $10 \mathrm{nM}$ everolimus. Seventy-two hours later, cells were collected, washed and resuspended in $300 \mu \mathrm{L}$ propidium iodide (Sigma-Aldrich). After 8h, 20,000 events from each sample were analyzed.

\section{Caspase-3/-7 activity assay}

To measure the activity of Caspase-3/-7, we used the Apo-One homogeneous Caspase-3/7-Assay kit (Promega): 10,000 cells were seeded per well, incubated for $24 \mathrm{~h}$ without treatment or with respective doses of BYL719 $(5-10 \mu \mathrm{M})$ or everolimus $(10 \mathrm{nM})$, and Caspase-3/7 activity was assessed according to the manufacturer's instructions. We compared all results of the BYL719- or everolimustreated cell lines to the vehicle-treated cell lines. For each experiment, the vehicle represented the highest DMSO concentration present in the respective experiment. The exact DMSO concentrations are detailed under 'Cell viability assessment' section.

\section{Protein extraction and Western blotting}

The cells were seeded into $10 \mathrm{~cm}$ plates and grown for $24 \mathrm{~h}$ in complete medium for Western blot analysis. Following medium exchange, cells were incubated with $10 \mathrm{nM}$ everolimus, either alone or in combination with BYL719 or AR-A014418. We compared all results to the vehicletreated cells. For each experiment the vehicle represented the highest DMSO concentration present in the respective experiment. The exact DMSO concentrations are detailed under 'Cell viability assessment' section. The incubation 
times were up to $72 \mathrm{~h}$. Western blotting was conducted as described previously (Reuther et al. 2016). A cell line screening to determine commonalities between both resistant cell lines (BON1 RR1 and BON1 RR2) in protein expression was performed using the following primary antibodies: pIRS-1 Ser612 (\#3203) (1:1000), IRS-1 (\#3407) (1:1000), pAkt (Ser473) (\#4060) (1:5000), Akt (\#2920) (1:5000), pTORC1 (S151) (\#3359) (1:1000), TORC1 (\#2587) (1:000), pp70S6K (T387/389) (\#9205) (1:2000), p70S6K (\#9234) (1:5000), pS6 (S240/244) (\#5354) (1:50000), S6 (\#2217) (1:5000), p4EBP1 (Ser65) (\#9451) (1:1000), 4EBP1 (\#9644) (1:10000), pCDK1 (Tyr15) (\#4539) (1:1000), CDK1 (\#9116) (1:2000), pEGFR (Y1068) (\#3777) (1:1000), EGFR (\#4267) (1:5000), pMet (Y1234/5) (\#3077) (1:2000), Met (\#3127) (1:5000), pGSK3 (S21/9) (\#9331) (1:2000), GSK3 (\#5676) (1:10000), LC3-A (\#4599) (1:1000), Caspase 3 (\#9662) (1:1000), cleaved Caspase 3 Asp175 (\#9661) (Cell Signaling) (1:1000), Actin (A5441) (Sigma) (1:50000), Bcl2 (610539) (BD Transduction Laboratories, Franklin Lakes, NJ, USA) (1:1000), CgA (ab68271) (Abcam) (1:100,000).

\section{Cell migration assay}

Cells were seeded at densities of 120,000 (BON1) cells per chamber in culture inserts (Ibidi, Munich, Germany). After $24 \mathrm{~h}$, the inserts were removed, and the cells were treated with $10 \mathrm{nM}$ everolimus for $48 \mathrm{~h}$. We compared the four cell lines BON1, BON1 Control DMSO, BON1 RR1 and BON1 RR2 to each other after treatment with $10 \mathrm{nM}$ everolimus. In this case the BON1 Control DMSO cell line functioned as control and was compared to the resistant cell lines. After $0 \mathrm{~h}$ and $48 \mathrm{~h}$ of incubation with everolimus, photographs of the gap between the two cell layers were taken (Zeiss, Axiovert 135 TV (microscope) and Zeiss, AxioCam MRm (camera)) and analyzed.

\section{Statistical analysis}

The results are displayed as mean \pm S.D. of at least three independently performed experiments. Each cell viability experiment consisted of at least 6 samples per substance concentration and incubation period. A priori tests considering the normal distribution and homogeneity of variances were performed applying the KolmogorovSmirnov test and Levene's test of the SPSS statistical package SPSS (version 13.0 for Windows, SPSS Inc. (2005)). When parametric criteria were met, an ANOVA comparison of means with a post hoc Tukey test or a two-tailed $t$-test was performed; when non-parametric criteria were met the
Kruskal-Wallis followed by the Mann-Whitney test was performed. When the one group was normalized to $100 \%$, comparisons were performed as one-sample tests.

To identify potential synergistic effects between BYL719 and everolimus on cell viability, we used Linear Mixed Effects Models. BYL719, everolimus (each in three different doses) and the interactions between both were considered as fixed effects, the trial as a random effect. If a significant negative interaction between BYL719 and everolimus on cell survival was found, we concluded a synergistic effect. One model was estimated for each cell line. These computations were done with R 3.3.3 (GNU General Public License; R Foundation, Vienna, Austria). For the analysis of the baseline differences in cell viability and Caspase 3/7 assay, we used linear mixed effects models too. While the cell line was considered as fixed, the trial was considered as random.

Statistical significance was assessed at $P<0.05$, besides for the Western blot analysis, where due to the exploratory character and the sample size, significance was assessed at $P<0.1$.

\section{Pilot mouse study: establishment of an orthotopic intrapancreatic everolimus-resistant tumor xenograft mouse model}

BON1 RR2 $\left(2 \times 10^{6}\right.$ in $20 \mu \mathrm{L}$ medium $)$ were implanted into the pancreas of 12-week-old female SCID mice (weight $20 \mathrm{~g})(n=4)$ as described by Soares et al. (2014) with minor changes. This technique was previously established by us to generate the orthotopic BON1 xenograft mouse model. Briefly, SCID mice were anesthetized by isoflurane and intraperitoneal injection of ketamine $(70 \mathrm{mg} / \mathrm{kg})$. After local shaving and disinfection, the abdominal area was opened by a $1 \mathrm{~cm}$ incision along the Linea Alba. The entire pancreatic body was then exposed on sterile gauze and retracted laterally on saline-soaked cotton tips in such way that enough solid pancreatic tissue was available for cell injection, before it was placed back into the abdominal cavity. Tumor growth was monitored once a week by a preclinical 1T PET/MRI (nanoScan, Mediso, Hungary) using a whole-body coil and T1-weighted gradient-echo and T2-weighted spin echo sequences. The metabolic activity of the engrafted tumor was estimated by ${ }^{18 F-F D G ~ P E T / M R I, ~ a n d ~ s o m a t o s t a t i n ~ r e c e p t o r ~} 2$ (SSTR2) levels were assessed by ${ }^{68} \mathrm{Ga}$-DOTATOC PET/CT (15 MBq injected i.v. respectively). When the tumors had reached a size of $\sim 1000 \mathrm{~mm}^{3}$, the experiment was terminated. Animal experiments were performed in accordance with the national and local guidelines for animal welfare and 
approved by the ethics committee of the state Berlin. All in vivo experiments were performed at the Berlin Experimental Radionuclide Imaging Center (BERIC), Charité - Universitätsmedizin Berlin, Germany.

\section{Results}

Following 24 weeks of permanent exposure to $10 \mathrm{nM}$ everolimus, we have, for the first time, been able to develop two independent stable everolimus-resistant panNET cell lines (BON1 RR1 and BON1 RR2). Both resistant cell lines did not regain sensitivity over time, and showed stable resistance after a drug holiday of 13 weeks. Moreover, both cell lines showed a GSK3 over-activation as a crucial commonality.

\section{Stable resistance}

After 24 weeks of permanent everolimus exposure, both cell lines (BON1 RR1 and BON1 RR2) showed strong reliable resistance to everolimus, whereas BON1 Control DMSO cells displayed no resistance (Fig. 2). We compared dose-response curves of the resistant cell lines to the dose-response curves of the non-resistant cell lines with $1 \mathrm{nM}-2 \mu \mathrm{M}$ everolimus and found resistance, i.e. at least a doubling of the $\mathrm{IC}_{50}$ in the resistant cell lines, compared to the sensitive controls, after 144-h everolimus treatment. $\mathrm{IC}_{50}$ calculations showed a 153 -fold increase $\left(\mathrm{IC}_{50}=5200 \mathrm{nM}\right)$ in BON1 RR1 and a 74 -fold increase $\left(\mathrm{IC}_{50}=2500 \mathrm{nM}\right)$ in BON1 RR2 cells when compared to the BON1 Control DMSO cells $\left(\mathrm{IC}_{50}=34 \mathrm{nM}\right.$ ) after 144-h everolimus treatment. BON1 Control DMSO cells demonstrated a significant decrease in cellular survival after re-application of $10 \mathrm{nM}$ everolimus for $144 \mathrm{~h}$, whereas
BON1 RR1 and BON1 RR2 cells showed a significant decrease in cellular viability only at $500 \mathrm{nM}$ and $60 \mathrm{nM}$, respectively (Fig. 2). The resistance was evaluated after freezing and thawing the cells again to confirm stable resistance. We performed additional dose-response curves after a drug holiday of 13 weeks and again found persistent stable resistance with an $\mathrm{IC}_{50}>2000 \mathrm{nM}$ in BON1 RR1 and BON1 RR2 cells.

\section{Morphologic changes, cell growth and neuroendocrine identity}

Everolimus-sensitive BON1 cells showed an oval shape with fibroblastic-like cellular extensions in some cells and regular cluster formation (Fig. 3A). Morphologic characteristics of everolimus-resistant cells displayed an amorphous, flattened cellular shape with lysosomelike bubbles and clumping conglomerates (Fig. 3A). The viable cell number of the resistant cell lines was slightly but significantly increased compared to the sensitive control cell line after $72 \mathrm{~h}$ without treatment $(P<0.001)$, suggesting more rapid proliferation (Fig. 3B).

We investigated the neuroendocrine identity of the resistant cell lines by assessing chromogranin A (CgA) by Western blot techology (Supplementary Fig. 1, see section on supplementary data given at the end of this article) and found strong expression of $\mathrm{CgA}$ in both resistant cell lines.

\section{Heterogeneity of BON1 RR1 and BON1 RR2}

We observed inhibition of mTORC1/p70S6K signaling to a differential extent between BON1 RR1 and BON1 RR2 after re-application of everolimus (Supplementary Fig. 1). By using two independently established

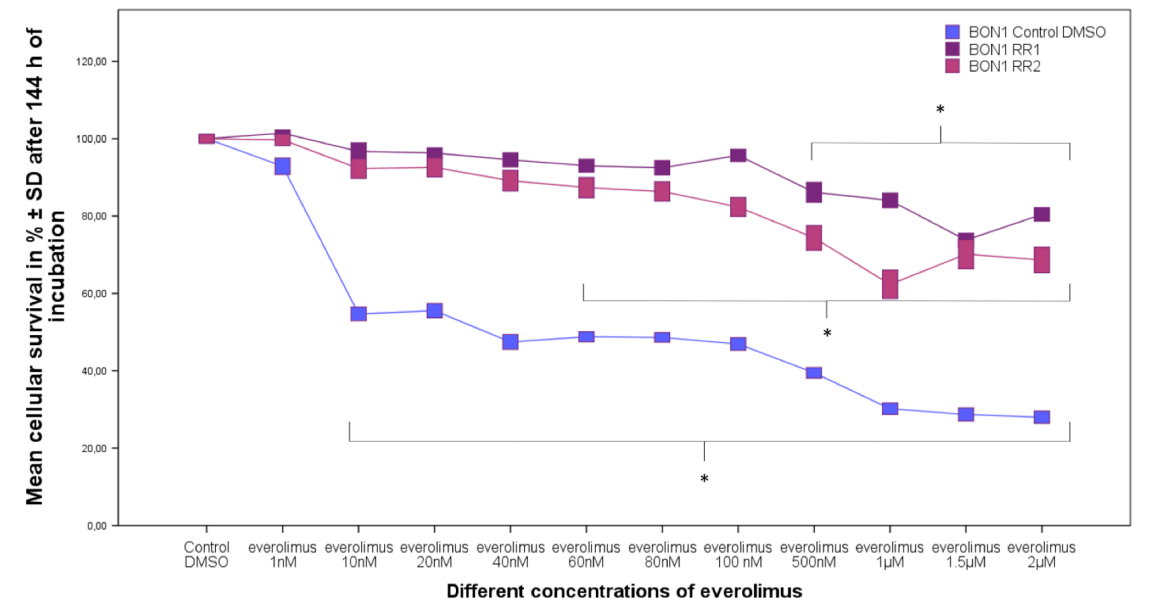

\section{Figure 2}

Effects of everolimus ( $1 \mathrm{nM}-2 \mu \mathrm{M})$ on cell survival of resistant (BON1 RR1 and BON1 RR2) and sensitive (BON1 Control DMSO) cell lines after $144 \mathrm{~h}$ of incubation with everolimus. The arithmetic means and standard deviation of at least three independent experiments are shown. Statistically significantly different results in comparison to BON1 Control DMSO are shown, considering $P<0.05$ as significant (*). A full colour version of this figure is available at https://doi. org/10.1530/ERC-18-0159. 


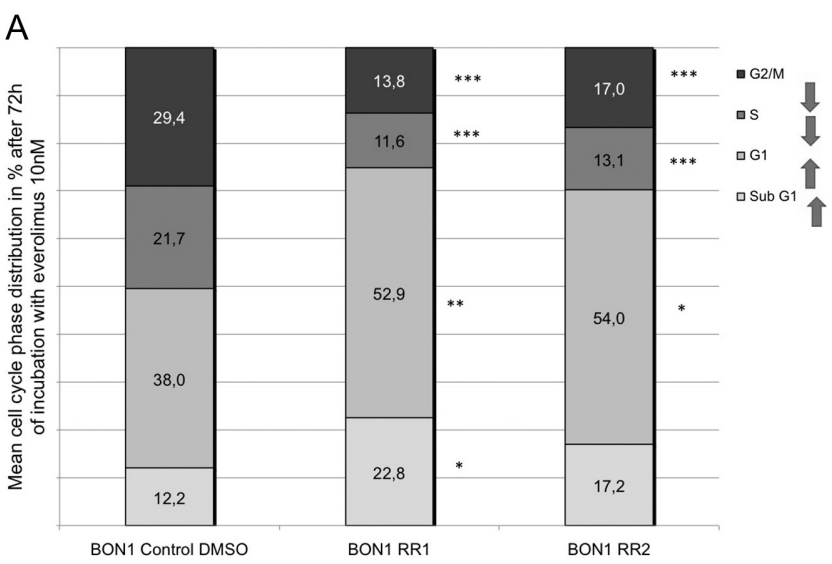

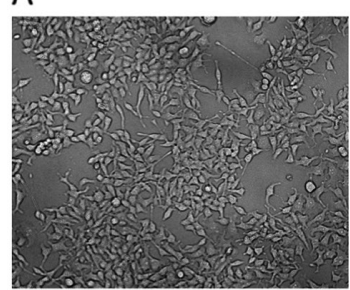
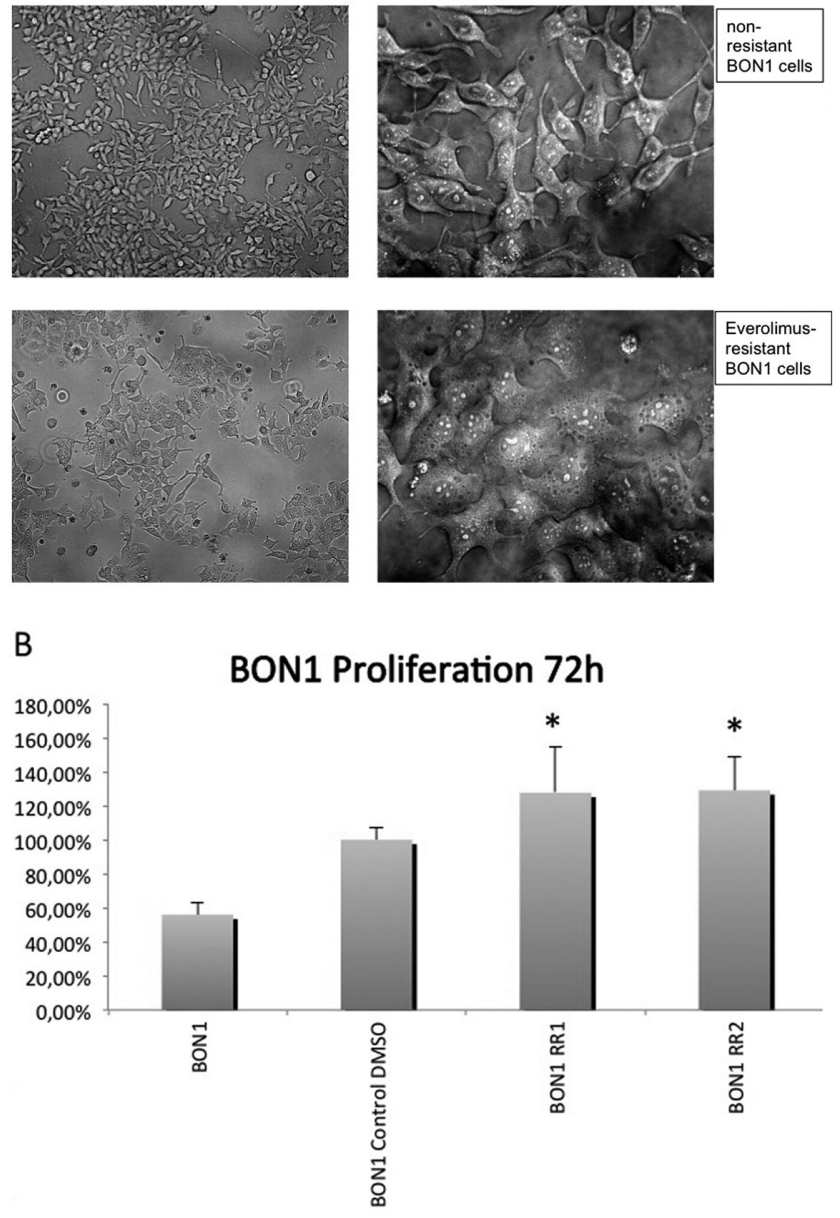

\section{Figure 3}

Everolimus resistant cells show morphologic changes. (A) Everolimusresistant cells (BON1 RR1 and BON1 RR2) displayed an amorphous, flattened cellular shape with lysosome-like bubbles and clumping conglomerates. (B) The viable cell number of the resistant cell lines was slightly but significantly increased compared to the sensitive control cell line after $72 \mathrm{~h}$ without treatment $(P<0.001)$, suggesting more rapid proliferation.

everolimus-resistant cell lines, we have attempted to reduce if not totally eliminate the bias due to tumor heterogeneity in response to long-term everolimus treatment.

\section{Everolimus resistance: G1 phase cell cycle arrest associated with reduced baseline expression of CDK1(cdc2) and of the autophagy marker LC3All}

Both resistant cell lines displayed a significant increase in sub-G1 phase and G1 phase in response to everolimus (Fig. 4A). Associated with the sub G1 increase and G1 phase cell cycle arrest, we found a decreased baseline CDK1(cdc2) expression and reduced baseline expression of the autophagy

\section{B}

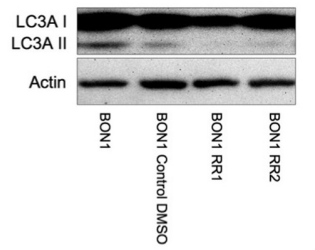

Figure 4

(A) Cell cycle analysis via FACS showed a significant increase in sub-G1 population and G1 phase cell cycle arrest in both resistant cell lines (BON1 RR1 and BON1 RR2) after $72 \mathrm{~h}$ everolimus treatment. The arithmetic means and standard deviation of at least three independent experiments are shown. Statistically significantly different results in comparison to BON1 Control DMSO are shown, considering $* P<0.05$; $* * P<0.01 ; * * * P<0.001$. (B) LC3A consists of two bands: LC3Al (upper band) and LC3All (lower band). Baseline LC3All expression level measured by Western blot analysis was decreased in BON1 RR1 and BON1 RR2, compared to BON1 and BON1 Control DMSO. A representative blot out of three independently performed experiments is shown.

marker LC3AII demonstrating reduced autophagy in BON1 RR1 and BON1 RR2 cells (Figs 4B and 5).

\section{Everolimus resistance increased baseline apoptosis}

Baseline cleaved caspase 3 as a marker of apoptosis was slightly increased in the resistant cell lines, compared to hardly detectable cleaved caspase 3 in the sensitive controls, indicating slightly stronger baseline apoptosis in the resistant cells (Fig. 6). In order to show these results more clearly, we additionally performed the more sensitive Caspase 3/7 assay and found the same results with significantly increased baseline apoptosis, in both resistant cell lines, compared to the sensitive controls $(P<0.01)$ (Fig. 6). Baseline expression of the antiapoptotic marker $\mathrm{Bcl} 2$ was much lower in the resistant cell lines compared to the sensitive controls and showed a lesser increase in response to BYL719 and everolimus treatment (Fig. 6). 

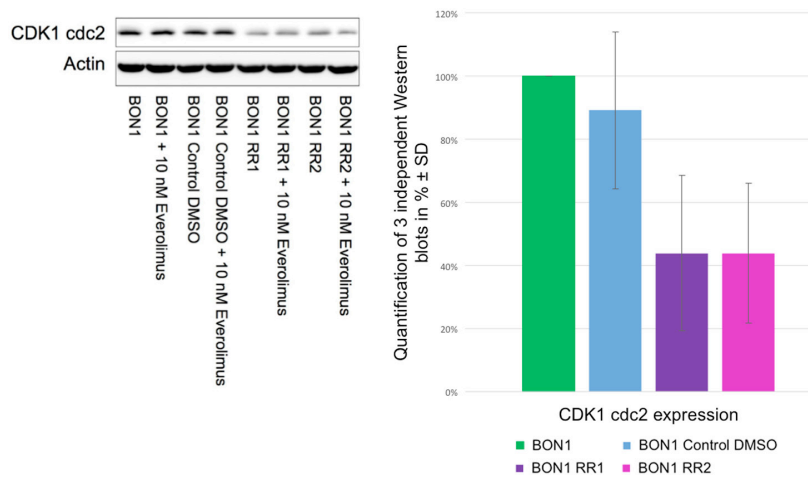

Figure 5

Western blot analysis via densitometry of $\mathrm{CDK} 1(\mathrm{cdc})$ showed a baseline decrease in CDK1(cdc2) expression levels in BON1 RR1 and BON1 RR2 cell lines, compared to the sensitive control cells. A representative blot out of three independently performed experiments is shown. For densitometry analysis the arithmetic means and standard deviation of at least three independent experiments are shown. A full colour version of this figure is available at https://doi.org/10.1530/ERC-18-0159.

\section{Everolimus resistance increased migration potential and baseline c-Met activation}

The migration assay reflected a significant increase in the migration potential of BON1 RR1/RR2 cells, compared to the sensitive control cell line, after treatment with $10 \mathrm{nM}$ everolimus (Fig. 7). Both resistant cell lines displayed stronger baseline activation of c-Met when compared to the control cells (Fig. 8).

\section{Everolimus resistance: baseline GSK3 $\alpha / \beta$ (GSK3) over-activation and strong BON1 RR1/RR2 cell viability reduction by specific GSK3 inhibition}

As GSK3 has been shown to be implicated in resistance to radio-, chemo- and molecular-targeted therapy (Shimura 2011, Martelli et al. 2014, McCubrey et al. 2014), we examined long-term treatment effects of everolimus on GSK3 (Fig. 9A). GSK3 is inhibited by phosphorylation. BON1 RR1/RR2 cells displayed a pronounced baseline decrease in phosphorylated/inhibited GSK3, and thus, GSK3 over-activation when compared to the sensitive control cell line (Fig. 9A). However, levels of activated and total Akt were similar in resistant and non-resistant cells with and without treatment (Fig. 9A). Akt was phosphorylated/activated in all resistant and sensitive cell lines after 24-h stimulation with everolimus (Fig. 9A).

GSK3 inhibition by the specific GSK3 inhibitor AR-A014418 caused a pronounced decrease in BON1 RR1/RR2 cell viability and - to a much lesser extent - in sensitive control cells (Fig. 9B). In both resistant and in the sensitive control cell line, Western blot analyses showed clear inhibition of GSK3 and an increase in the autophagy marker LC3AII in response to AR-A014418 treatment (Fig. 9C). However, combination treatment of everolimus plus AR-A014418 did not enhance the inhibitory effect of single AR-A014418 treatment on cell viability in resistant cells (Supplementary Fig. 2).

We also performed Western blots on the combination of everolimus plus AR-A014418 and, while single AR-A014418 treatment led to strong GSK3 $\alpha$ inhibition in the resistant cell lines, combination treatment caused no stronger GSK3 $\alpha$ inhibiton compared to single AR-A014418 treatment (Supplementary Fig. 2); this may help explain the absence of a synergistic effect.

\section{Everolimus resistance: lower baseline IRS-1 protein levels}

Interestingly, baseline IRS-1 protein levels showed a decrease in BON1 RR1 and BON1 RR2 cells compared to parental BON1 and BON1 Control DMSO cells (Fig. 6).

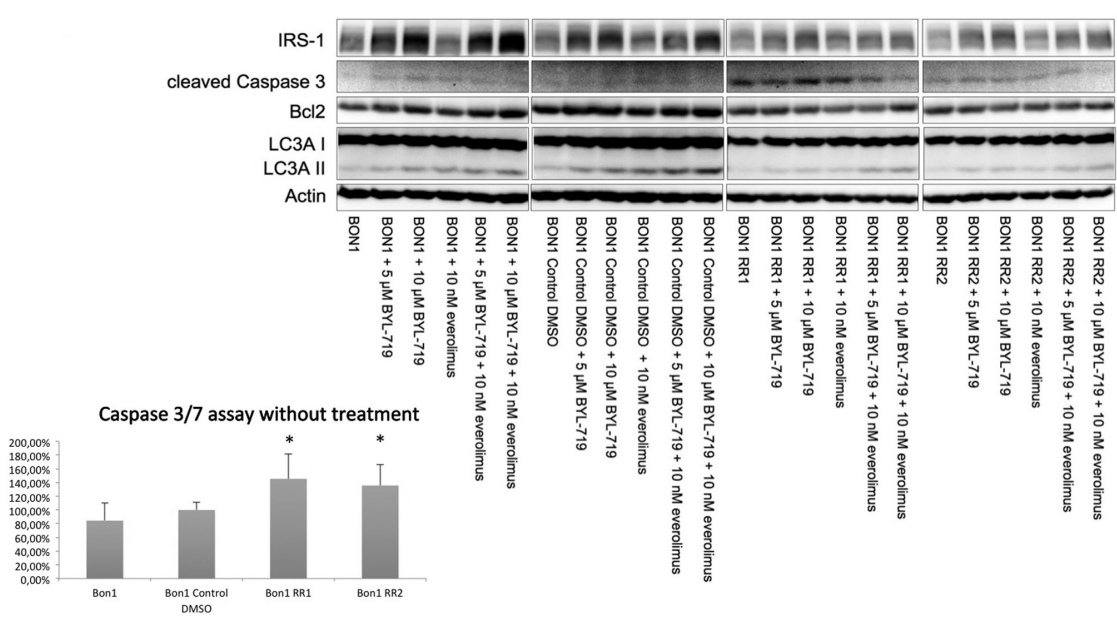

\section{Figure 6}

In the resistant cell lines, Western blot analysis showed a baseline decrease in IRS-1 protein levels, an increase in cleaved Caspase 3 and a decrease in anti-apoptotic Bcl-2 as a sign of increased apoptosis, as well as a decrease in LC3All as a sign of decreased autophagy. LC3A consists of two bands: LC3AI (upper band) and LC3All (lower band). Caspase 3/7 assay showed significantly increased apoptosis in both resistant cell lines, compared to the sensitive control cell line $(P<0.01)$. 
For pIRS-1, the differences between the different cell lines were minor according to the Western blot quantification. Western blot quantifications for IRS-1 and pIRS-1 are shown in Supplementary Fig. 3. The effects of BYL719 and everolimus treatment on IRS-1 are described below.

Total mTORC1 showed no clear differences between resistant cells and non-resistant cells (Supplementary Fig. 4). No activated pmTORC1 could be detected in our cell lines.

\section{Dual-targeting approach with the PI3Ko inhibitor BYL719 overcame everolimus resistance and restored sensitivity through GSK3 inhibition, increased autophagy and decreased apoptosis}

Combination treatment with the PI3K $\alpha$ inhibitor BYL719 plus everolimus overcame everolimus resistance and restored treatment sensitivity (Fig. 10A). A significantly stronger decrease in cellular survival after combination treatment compared to single substance treatment could be observed in both resistant cell lines (Fig. 10A). We moreover studied additional dose-response relationships combining low doses of $1-10 \mathrm{nM}$ everolimus with $1-5 \mu \mathrm{M}$ BYL719 and found significant synergistic effects at almost all drug doses tested in all cell lines, including both
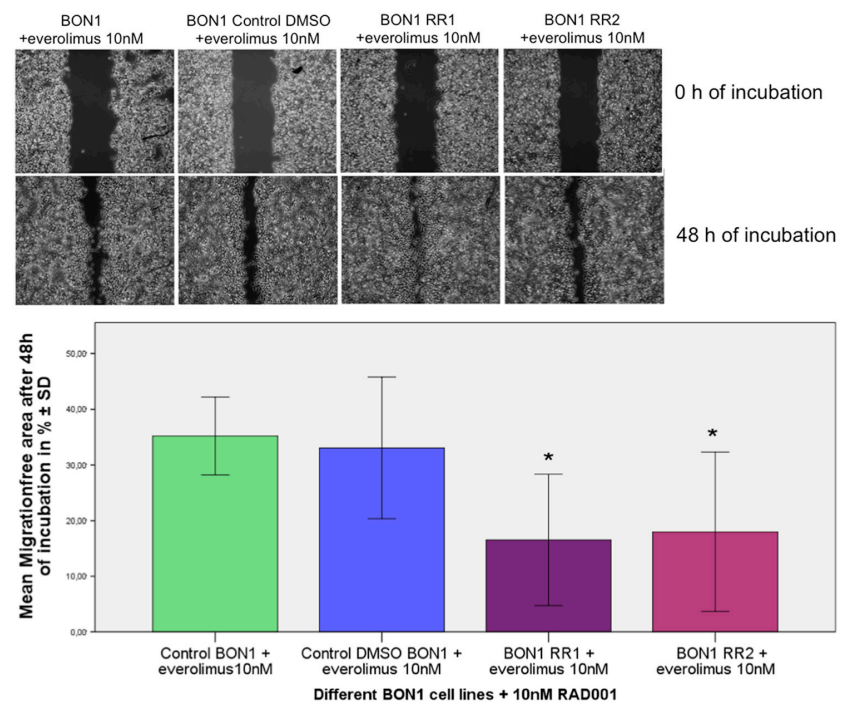

Figure 7

Everolimus-resistant cells showed a significantly increased migration potential with a significantly smaller migration gap after $48 \mathrm{~h}$ of everolimus treatment. The arithmetic means and standard deviation of at least three independent experiments are shown. Statistically significantly different results in comparison to BON1 Control DMSO are shown, considering $* P<0.05$. A full colour version of this figure is available at https://doi.org/10.1530/ERC-18-0159. resistant cell lines $\left({ }^{*} P<0.05\right)$ (Supplementary Figs 5, 6, 7 and 8 ). This synergistic inhibitory effect on cell survival after the BYL719/everolimus combination treatment was associated with inhibition of GSK3, EGFR, p70S6K and 4EBP1 signaling, as well as showing an increase in IRS-1 protein levels in BON1 RR1/RR2 cells (Figs 6 and 10B). In both sensitive cell lines, everolimus alone already led to strong GSK3 phosphorylation/inhibition. In BON1 RR1/RR2 cells, single application of everolimus led to lower or no phosphorylation/inhibition of GSK3, but the combination treatment induced stronger inhibition of GSK3, compared to each drug separately. A different response of IRS-1 protein levels to everolimus and BYL719 treatment between resistant and non-resistant cell lines was observed: while sensitive control cells showed a slight increase in IRS-1 protein levels after everolimus treatment, the resistant cells showed a lesser or no IRS-1 increase (Fig. 6 and Supplementary Fig. 3A). In the nonresistant cells, BYL719 treatment alone was accompanied by increased IRS-1 protein expression, while in the resistant cells a lesser, but nevertheless clear, increase in IRS-1 protein levels was observed in response to BYL719 treatment (Fig. 6 and Supplementary Fig. 3A).

The BYL719/everolimus combination treatment showed a strong increase in IRS-1 expression in the nonresistant BON1 and BON1 Control DMSO cells, and a lesser, but still clear, increase in IRS-1 protein levels in the resistant cells (Fig. 6 and Supplementary Fig. 3A).

We studied the differences concerning cell death mechanisms between resistant and non-resistant cell lines in response to BYL719/everolimus treatment:
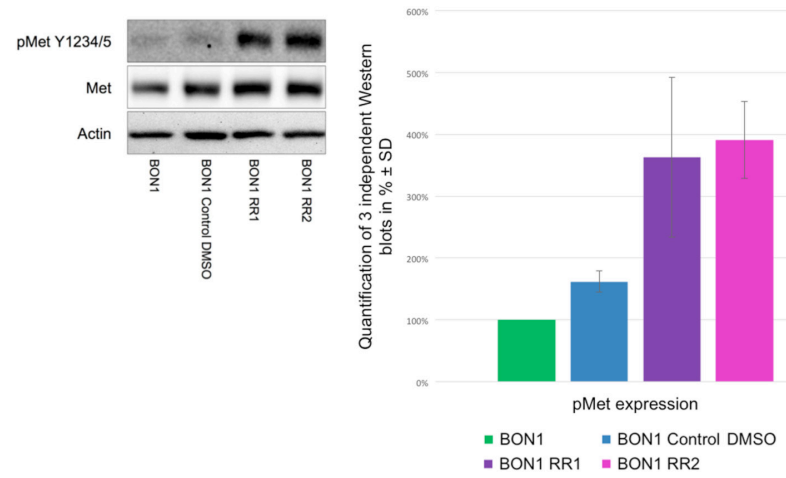

Figure 8

Western blot analysis via densitometry of phosphorylated/activated c-Met and total c-Met in resistant (BON1 RR1 and BON1 RR2) and sensitive control cells showed an increase in phosphorylated/activated c-Met in the resistant cell lines. A representative blot out of three independently performed experiments is shown. For densitometry analysis the arithmetic means and standard deviation of at least three independent experiments are shown. A full colour version of this figure is available at https://doi.org/10.1530/ERC-18-0159. 


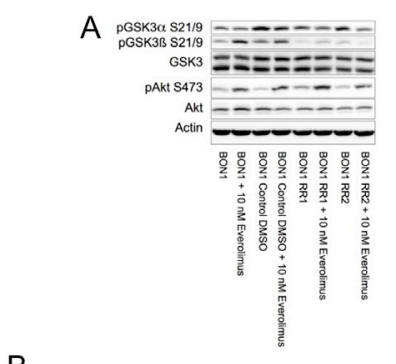

B
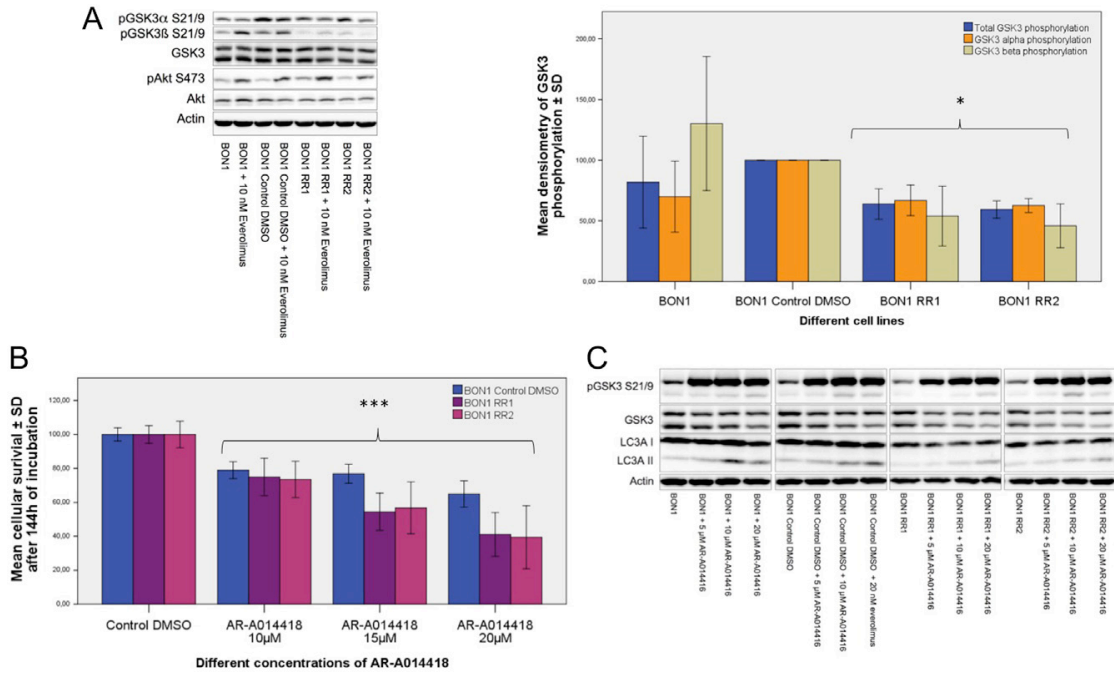

Figure 9

GSK3 over-activation in the resistant cell lines. (A) Both everolimus-resistant cell lines showed significantly enhanced activation of GSK3 $\alpha / \beta$ (GSK3) compared to the sensitive control cell line (BON1 Control DMSO) and a significantly stronger activation of GSK3 $\beta$ compared to the parental BON1 cells, but stable phosphorylation/activation of AKT after $24 \mathrm{~h}$ of incubation with everolimus. A representative blot out of three independently performed experiments is shown. Statistically significantly different results $\left(^{*}\right)$ in comparison to BON1 Control DMSO are shown. (B) Single substance treatment of AR-A014418 (10-20 $\mathrm{MM})$ significantly decreased cellular survival in all cell lines tested after $144 \mathrm{~h}$ of incubation, although much stronger in BON1 RR1 and BON1 RR2, compared to the sensitive control cell line. The arithmetic means and standard deviation of at least three independent experiments are shown. Statistically significant differences in comparison to either single substance treatment are shown, considering $* * * P<0.001$. (C) Western blot analysis showed inhibition of GSK3 and an increase in the autophagy marker LC3All in response to the selective GSK3 $\alpha / \beta$ inhibitor AR-A014418. LC3A consists of two bands: LCBAI (upper band) and LC3All (lower band). A full colour version of this figure is available at https://doi.org/10.1530/ ERC-18-0159.
We found that in BON1 RR1/RR2 cells, BYL719/everolimus combination treatment was accompanied by an increase in the autophagy marker LC3AII, compared to each drug separately, indicating an increase in autophagy in response to the BYL719/everolimus combination treatment (Fig. 6).

In the sensitive control cells, the Caspase 3/7 assay showed apoptosis induction at $24 \mathrm{~h}$ with BYL719 treatment, but not in BON1 RR1/RR2; everolimus treatment had no influence on apoptosis induction, while the everolimus/BYL719 combination treatment significantly decreased apoptosis in BON1 RR1/RR2 cells compared to each drug separately, but had no significant influence on apoptosis induction in the sensitive control cells (Supplementary Fig. 9). This was consistent with a decrease in cleaved Caspase 3 in the resistant cell lines after BYL719/everolimus combination treatment, compared to treatment with each drug separately.

\section{Transferability of the resistant cell line model to an orthotopic intrapancreatic xenograft mouse model}

In an in vivo pilot study, we were able to transfer our resistant cell line model to an orthotopic xenograft SCID mouse model with intrapancreatic tumor growth $(n=4)$. Supplementary Figure 10A, B and C show an example of the growth of an intrapancreatic BON1 RR2 tumor in a SCID mouse: 14 days after tumor cell injection into the pancreas, a detectable tumor developed and reached a size of $\sim 1000 \mathrm{~mm}^{3}$ around 5 weeks after first detection by MRI (Supplementary Fig. 10A, B and C). Tumor size and tissue morphology were determined by T2w imaging. The resistant tumors showed a similar growth rate and tumor morphology as the native BON1 tumors. When the tumors grew bigger, necrotic areas in the tumor core increased (Supplementary Fig. 10A, B and C) towards the end of the experiment. The glucose uptake (standard uptake value (SUV)) calculated from ${ }^{18}$ F-FDG PET confirmed that the tumors were metabolically active (Supplementary Fig. 10E). As expected, ${ }^{68} \mathrm{Ga}-\mathrm{DOTATOC}$ PET scanning showed no uptake in the resistant tumors, confirming the absence of somatostatin receptor-2 (Supplementary Fig. 10F).

\section{Discussion}

\section{Stable resistance and morphologic changes}

In our BON1 in vitro model, permanent long-term treatment with a constant low dose of $10 \mathrm{nM}$ everolimus over 24 weeks caused stable resistance to everolimus. In contrast to the study of Vandamme et al., who found a complete reversal of resistance after a drug holiday of 10-12 weeks (Vandamme et al. 2016), we demonstrated stable persistent resistance after a drug holiday of 13 weeks. 


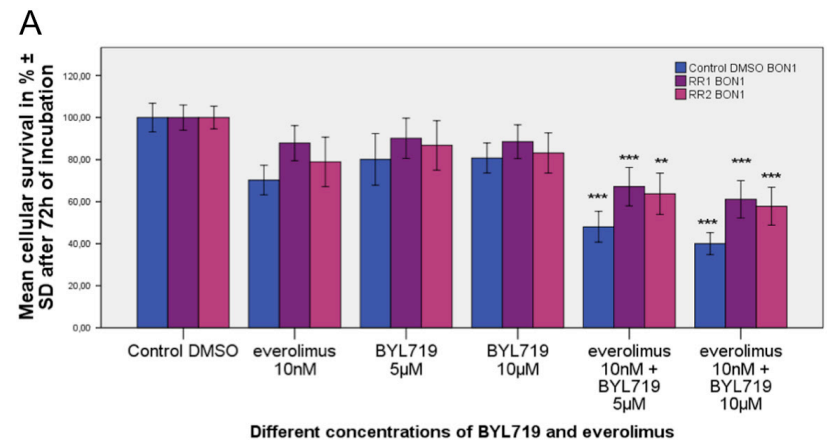

B

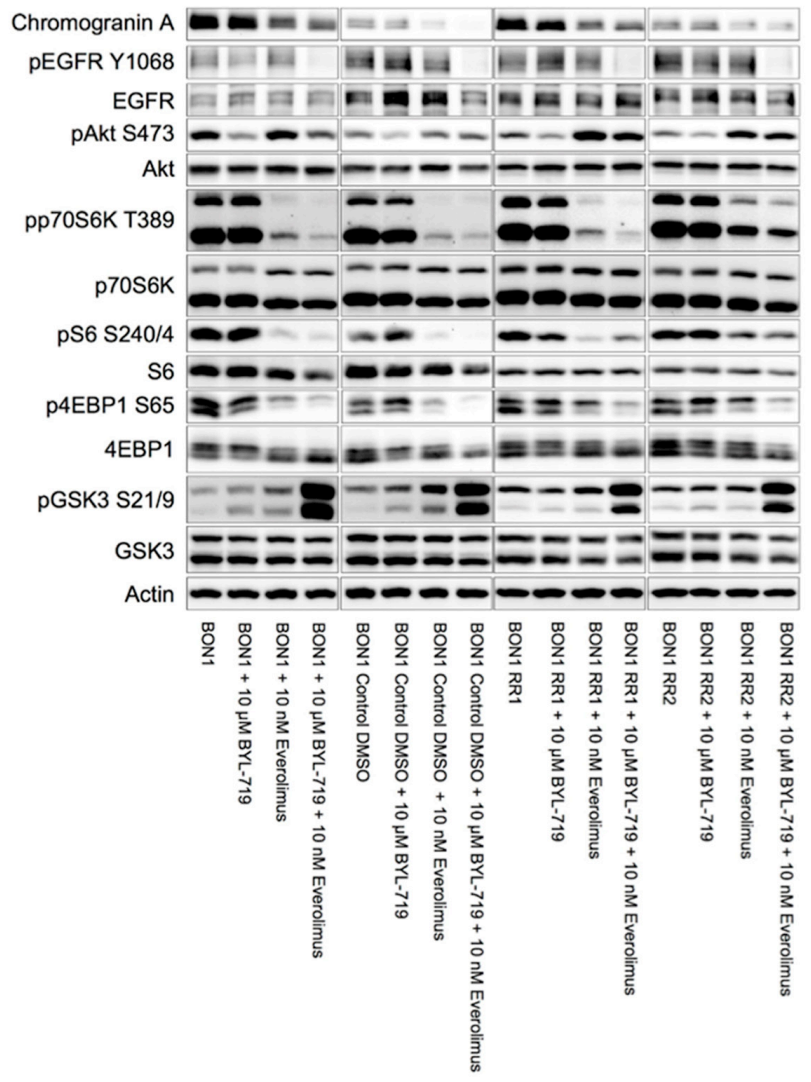

\section{Figure 10}

Dual-targeting approach with the PI3K $\alpha$ inhibitor BYL719 overcame acquired everolimus resistance and restored sensitivity through inhibition of GSK3, EGFR, p7056K and 4EBP1 signaling. (A) Combination treatment of everolimus plus BYL719 showed a significantly enhanced inhibitory effect on cell viability compared to single substance treatment in all tested cell lines. Cells were incubated with BYL719 $(5 \mu \mathrm{M}$ and $10 \mu \mathrm{M})$ and everolimus $(10 \mathrm{nM})$ alone and in combination for $72 \mathrm{~h}$. The arithmetic means and standard deviation of at least three independent experiments are shown. Statistically significantly different results in comparison to either single substance treatment are shown, considering $* P<0.05$; $* * P<0.01 ; * * * P<0.001$. (B) Protein levels of components from the EGFR-Akt (pEGFR, EGFR, pAkt, Akt), mTORC1-p70S6K (pp7056, p70S6K, pS6, S6, p4EBP, 4EBP1) and GSK3 (pGSK3, GSK3) signaling pathway are displayed. Inhibition of GSK3, EGFR, p7056K and 4EBP1 signaling was observed after combination treatment. A representative blot out of three independently performed experiments is shown. A full colour version of this figure is available at https://doi.org/10.1530/ERC-18-0159.
Everolimus-resistant BON1 cells have previously been described as developing an elongated shape with fewer cell-to-cell contacts (Passacantilli et al. 2014) or to cause no morphologic changes (Vandamme et al. 2016). We, however, found an amorphous, flattened cellular shape with lysosome-like bubbles and clumping conglomerates as a morphologic feature of everolimus-resistant BON1 cells. The differences in stability of resistance and morphologic appearance between the studies may be explained by experimental design differences: Passacantilli et al. treated panNETs cells permanently only for 8 weeks with $10 \mathrm{nM}$ everolimus and did not confirm stable resistance (Passacantilli et al. 2014); Vandamme et al. followed a pulsed-selection experimental design (McDermott et al. 2014) by permanently augmenting everolimus doses up to $1 \mu \mathrm{M}$, which might be less clinically relevant due to the application of high drug doses out of the clinically relevant range (around 8-59nM) (Budde et al. 2016, Vandamme et al. 2016).

Since BON1 RR1 and BON1 RR2 have both been developed on the same genetic background and BON1 cells have a higher proliferative index than the typical well differentiated neuroendocrine tumor, we aimed to confirm our model in the novel slow growing human pancreatic NET cell line NT-3 (Benten et al. 2018). Unfortunately, due to the slow growing nature of NT-3 cells, these experiments are still ongoing now for more than 12 months. The initial results showed a gradual increase in proliferation over time in the presence of doses up to four times of the $\mathrm{IC}_{50}$ value $(4 \mathrm{nM})$ of the parental cell line, and we observed similar changes in morphology as in resistant BON1 cells with a switch to a flattened and more pitted appearance under continuous everolimus exposure (unpublished results).

\section{Heterogeneity of BON1 RR1 and BON1 RR2}

Tumor heterogeneity has been suggested as a possible mechanism of everolimus resistance (Vandamme et al. 2016) and could be the driving force of sub-clone selection of the most resistant phenotype in response to treatment (Marusyk et al. 2014, Vandamme et al. 2016). Our data are compatible with this theory since both resistant cell lines established in parallel do not show a completely identical phenotype with slightly different effects of everolimus on p70S6K phosphorylation in both cell lines. The novelty of our work lies in its ability to elicit common features of both independently established everolimus-resistant cell lines in order to reduce the bias due to tumor heterogeneity. 
Everolimus resistance: $\mathbf{G} 1$ phase cell cycle arrest, reduced baseline autophagy and increased baseline apoptosis

Consistent with an increase in G1 phase cell cycle arrest and sub-G1 population in the resistant cell lines in response to everolimus, we observed a baseline decrease in CDK1(cdc2) expression. CDK1(cdc2) is a key regulator of the mitotic transition (Nurse 1990) and its inactivation causes exit from mitosis and stabilizes G1 phase (Potapova et al. 2009). The G1 phase cell cycle arrest/sub-G1 increase in the resistant cell lines might be associated with the observed decrease in baseline autophagy. Inhibition of autophagy has shown to be linked to a G1 phase cell cycle arrest, sub-G1 increase and apoptosis induction in different cancer entities (Choi et al. 2013, Liu et al. 2014, Almasi et al. 2018). Nevertheless, the decrease in autophagy seems unexpected in the context of resistance since mTORC1 inhibitor-induced autophagy has previously been described as a potential mechanism of promoting tumor cell resistance: inhibition of autophagy increased everolimus efficacy in NET cells (Avniel-Polak et al. 2016, Avniel et al. 2018). The decrease in the autophagy marker LC3AII observed in the resistant cell lines might be a mechanism of adaption to the permanent induction of autophagy in the presence of the mTORC1 inhibitor everolimus. This might indicate a sensitive balance of the dual effects of autophagy as a protective mechanism for the cancer cell on the one hand and as a mediator of cell death on the other (Sui et al. 2013).

Since apoptosis negatively correlates with autophagy (Liao et al. 2012, Sui et al. 2013, Avniel-Polak et al. 2016, Mejias-Pena et al. 2017), the decrease in autophagy in the resistant cell lines might cause the observed increase in apoptosis. All these effects might be due to GSK3 overactivation. GSK3 over-activation, which is discussed below in detail, has previously been reported to be directly associated with G1 cell cycle arrest, decreased autophagy and increased apoptosis (Li et al. 2011, Giancotti 2014, Maurer et al. 2014, Weikel et al. 2016, Zhang et al. 2016, Aristizabal Prada et al. 2017) and to be a crucial feature of cancer cell resistance to chemotherapy, radiotherapy and targeted therapies (Domoto et al. 2016, McCubrey et al. 2016).

\section{Everolimus resistance increased migration potential and c-Met activation}

BON1 RR1 and BON1 RR2 cells displayed significantly increased migration potential in response to everolimus treatment and baseline c-Met over-activation. Temsirolimus-(mTORC1 inhibitor)-resistant renal cell carcinoma cells also showed enhanced migration potential (Juengel et al. 2014). Mis-regulation, overexpression or gene amplification of the RTK c-Met have been identified to play a crucial role in tumor invasion, motility and metastasis formation associated with poor prognosis (Di Renzo et al. 1992, Camp et al. 1999, Chen et al. 1999, Takeo et al. 2001, Ma et al. 2003, Song et al. 2010). However, in previous studies, we demonstrated that specific c-Met inhibition by either knock-down experiments with siRNA or the specific c-Met inhibitor INC280 could neither decrease cellular viability nor cellular migration in NET cells in vitro (Reuther et al. 2016). C-Met activation might be rather indirectly associated with cellular migration potential in NET cells in vitro through activation of alternative pathways, such as the PI3K-Akt-mTORC1 pathway (Engelman et al. 2007).

\section{Everolimus resistance: baseline GSK3 over-activation and decrease in IRS-1 protein levels}

A feedback activation of RTKs such as the insulin receptor due to mTORC1 inhibition has previously been reported (Chandarlapaty et al. 2011). The feedback activation of PI3K-Akt signaling by the mTORC1 inhibitor everolimus via disinhibition/activation of IRS-1 has been discussed as a possible cause of resistance in NETs (Fig. 1, red arrows) (O'Reilly et al. 2006, Zitzmann et al. 2010, Vandamme et al. 2016). We have indeed found that pro-survival signaling of the PI3K-Akt pathway through Akt phosphorylation/activation upon everolimus re-application persisted in BON1 RR1 and BON1 RR2, as described previously in long-term everolimus-treated panNET cells (Passacantilli et al. 2014). Therefore, we speculate that there was permanent PI3K/Akt activation in the presence of persisting everolimus treatment during the development of resistance. Constitutively active PI3K has previously been reported to induce a reduction in IRS-1/2 protein levels (Pirola et al. 2003, Wada 2009). Therefore, IRS-1 downregulation observed in the resistant cell lines might be a compensatory escape mechanism in response to chronic PI3K/Akt over-activation, similar to the mechanism of development of insulin resistance (Pirola et al. 2003). Different IRS-1-induced signaling pathways have previously been reported to inhibit GSK3 (Cohen \& Frame 2001, Wada 2009, Maurer et al. 2014, Vandamme et al. 2016). Therefore, lower baseline IRS-1 protein levels in the resistant cells may lead to lower GSK3 inhibition and thus stronger GSK3 activation. 
Since baseline Akt activity or expression was not changed in the resistant cells, compared to the sensitive controls, it is unlikely that GSK3 is over-activated through modulation of the Akt pathway, but more likely through an alternative pathway. These mechanisms need to be investigated in future studies in NETs.

Various studies have demonstrated an association between IRS-1/GSK3 $\alpha / \beta$ deregulation and tumorigenesis (Wada 2009, McCubrey et al. 2016). GSK3 over-activation may promote the development of everolimus resistance, as recently reviewed for GSK3 in the context of resistance to chemotherapy, radiotherapy and targeted therapies (Domoto et al. 2016, McCubrey et al. 2016). Similar effects were observed in transfected MCF-7 breast cancer cells, where a constitutively active GSK3 construct showed resistance to the mTORC1 inhibitor rapamycin (McCubrey et al. 2014).

In order to prove the importance of constitutivelyactive GSK3 in everolimus-resistant panNET cells, we treated BON1 RR1/RR2 cells with the selective GSK3 inhibitor AR-A014418 and found a striking decrease in cellular viability in BON1 RR1/RR2, and to a lesser extent in sensitive control cells, associated with an increase in the autophagy marker LC3AII. However, unexpectedly, combination treatment of AR-A014418 plus everolimus did not enhance the inhibitory effects of single AR-A014418 treatment. The absence of synergism in the AR-A014418/ everolimus combination treatment may be explicable by GSK3 $\alpha$ inhibition being similar in response to the combination treatment compared to single treatment with AR-A014418 in the resistant cell lines.

\section{Dual-targeting approach with the PI3K $\alpha$ inhibitor BYL719 overcame acquired everolimus resistance}

In a previous study on different NET cell lines, the selective PI3Ka inhibitor BYL719 showed synergistic anti-proliferative effects in combination with everolimus through strong GSK3 inhibition (Nölting et al. 2017). In contrast to AR-A014418/everolimus combination treatment, the combination of everolimus with BYL719 was synergistic at low therapeutically-relevant doses in both resistant cell lines and restored everolimus sensitivity through more potent GSK3 inhibition, compared to each drug separately; this was associated with IRS-1 up-regulation, increased autophagy associated with decreased apoptosis, and an inhibition of EGFR, 4EBP1 and p70S6K. This is consistent with our previous study showing that selective GSK3 inhibition led to inhibition of EGFR, p70S6K and 4EBP1 and enhanced the autophagy marker LC3AII in BON1 cells (Aristizabal Prada et al. 2017). It has previously been reported that inhibition of GSK3 restored autophagy (Weikel et al. 2016, Zhang et al. 2016, Aristizabal Prada et al. 2017) and re-sensitized different tumor entities to chemotherapy, radiotherapy or targeted therapy (Domoto et al. 2016).

Similar combination approaches using PI3K inhibitors (BEZ235 or BKM120), although without taking GSK3 signaling into account, have previously been shown to overcome reversible everolimus resistance (Passacantilli et al. 2014, Vandamme et al. 2016). BYL719 is currently being investigated in a late phase 3 clinical study (SOLAR-I) for breast cancer (NCT02437318) and will probably enter clinical use. Moreover, a phase $1 \mathrm{~b}$ clinical study is currently evaluating the safety of BYL719 plus everolimus in advanced breast cancer, renal cell cancer and pancreatic tumors including panNETs (NCT02077933). Therefore, we provide novel data on the potentially clinically relevant PI3Ka inhibitor BYL719. GSK3 inhibition by BYL719 might be considered as second-line treatment in everolimus-resistant panNETs if indeed permanent GSK3 over-activation, potentially in combination with decreased IRS-1 protein levels, can be demonstrated as a central mechanism of resistance in vivo.

\section{Conclusions and perspectives}

In this study, we established two stable everolimus-resistant panNET (BON1) cell lines. The mechanisms of resistance may include G1 cell cycle arrest, decreased CDK1/cdc2 expression, reduced autophagy, increased apoptosis and migration potential potentially due to permanent GSK3 over-activation compatible with downregulation of IRS-1 protein levels. The dual-targeting approach with the PI3K $\alpha$ inhibitor BYL719 restored treatment sensitivity through GSK3 inhibition, IRS-1 upregulation and increased autophagy in the resistant cells. In a pilot study, we have already transferred our resistant cell line model to an orthotopic intrapancreatic tumor xenograft mouse model, and this may represent a valid basis to validate our in vitro findings of this first stable everolimus-resistant cell line model and translate it into clinical practice.

\section{Supplementary data}

This is linked to the online version of the paper at https://doi.org/10.1530/ ERC-18-0159. 


\section{Declaration of interest}

The authors declare that there is no conflict of interest that would prejudice the impartiality of the research reported. C J A and A B G have received research contracts (Ipsen, Novartis), lecture honoraria (Ipsen, Novartis) and advisory board honoraria (Novartis). J $\mathrm{S}$ has received research contracts (Novartis) and lecture honoraria (Novartis, Ipsen). S N has received a research contract (Novartis) and lecture honoraria (Ipsen).

\section{Funding}

E T Aristizabal Prada has received a scholarship from FAZIT-Stiftung (http:// www.fazit-stiftung.de). This work was supported by a Young Investigator Research Grant (YING) to S N, project number RAFI 029, from Novartis Pharma GmbH, Nürnberg, Germany. This research was supported, in part, by the Intramural Research Program of the NIH, NICHD and by the Deutsche Forschungsgemeinschaft (DFG) (within the CRC/Transregio 205/1 'The Adrenal: Central Relay in Health and Disease').

\section{Acknowledgements}

The authors thank Jakob Albrecht (Department of Nuclear Medicine, Charite Berlin) for performing the implantation of everolimus-resistant BON1 cells into SCID mice and Berlin Experimental Radionuclide Imaging Center (BERIC), Charité - Universitätsmedizin Berlin, Germany for in vivo experiments.

\section{References}

Almasi S, Kennedy BE, El-Aghil M, Sterea AM, Gujar S, Partida-Sanchez S \& El Hiani Y 2018 TRPM2 channel-mediated regulation of autophagy maintains mitochondrial function and promotes gastric cancer cell survival via the JNK-signaling pathway. Journal of Biological Chemistry 293 3637-3650. (https://doi.org/10.1074/jbc. M117.817635)

Aristizabal Prada ET \& Auernhammer CJ 2018 Targeted therapy of gastroenteropancreatic neuroendocrine tumours: preclinical strategies and future targets. Endocrine Connections 7 R1-R25. (https://doi.org/10.1530/EC-17-0286)

Aristizabal Prada ET, Weis C, Orth M, Lauseker M, Spoettl G, Maurer J, Grabowski P, Grossman A, Auernhammer CJ \& Nölting S 2017 GSK3alpha/beta: a novel therapeutic target for neuroendocrine tumors? Neuroendocrinology 106 335-351. (https://doi. org/10.1159/000481887)

Auernhammer CJ, Spitzweg C, Angele MK, Boeck S, Grossman A, Nölting S, Ilhan H, Knosel T, Mayerle J, Reincke M, et al. 2017 Advanced neuroendocrine tumours of the small intestine and pancreas: clinical developments, controversies, and future strategies. Lancet Diabetes and Endocrinology 6 404-415. (https://doi. org/10.1016/S2213-8587(17)30401-1)

Avniel S, Leibowitz G, Doviner V, Gross DJ \& Grozinsky-Glasberg S 2018 Combining chloroquine with RAD001 inhibits tumor growth in a NEN mouse model. Endocrine-Related Cancer 25 677-686. (https:// doi.org/10.1530/ERC-18-0121)

Avniel-Polak S, Leibowitz G, Riahi Y, Glaser B, Gross DJ \& GrozinskyGlasberg S 2016 Abrogation of autophagy by chloroquine alone or in combination with mTOR inhibitors induces apoptosis in neuroendocrine tumor cells. Neuroendocrinology 103 724-737. (https://doi.org/10.1159/000442589)

Benten D, Behrang Y, Unrau L, Weissmann V, Wolters-Eisfeld G, BurdakRothkamm S, Stahl FR, Anlauf M, Grabowski P, Mobs M, et al. 2018 Establishment of the first well-differentiated human pancreatic neuroendocrine tumor model. Molecular Cancer Research 16 496-507. (https://doi.org/10.1158/1541-7786.MCR-17-0163)
Briest F \& Grabowski P 2014 PI3K-AKT-mTOR-signaling and beyond: the complex network in gastroenteropancreatic neuroendocrine neoplasms. Theranostics 4 336-365. (https://doi.org/10.7150/ thno.7851)

Budde $\mathrm{K}$, Zonnenberg BA, Frost M, Cheung W, Urva S, Brechenmacher T, Stein K, Chen D, Kingswood JC \& Bissler JJ 2016 Pharmacokinetics and pharmacodynamics of everolimus in patients with renal angiomyolipoma and tuberous sclerosis complex or lymphangioleiomyomatosis. British Journal of Clinical Pharmacology 81 958-970. (https://doi.org/10.1111/bcp.12834)

Camp RL, Rimm EB \& Rimm DL 1999 Met expression is associated with poor outcome in patients with axillary lymph node negative breast carcinoma. Cancer 86 2259-2265. (https://doi.org/10.1002/ (SICI) 1097-0142(19991201)86:11<2259::AID-CNCR13>3.0.CO;2-2)

Capozzi M, Caterina I, De Divitiis C, von Arx C, Maiolino P, Tatangelo F, Cavalcanti E, Di Girolamo E, Iaffaioli RV, Scala S, et al. 2015 Everolimus and pancreatic neuroendocrine tumors (PNETs): activity, resistance and how to overcome it. International Journal of Surgery 21 (Supplement 1) S89-S94. (https://doi.org/10.1016/j. ijsu.2015.06.064)

Capurso G, Fendrich V, Rinzivillo M, Panzuto F, Bartsch DK \& Delle Fave G 2012 Novel molecular targets for the treatment of gastroenteropancreatic endocrine tumors: answers and unsolved problems. International Journal of Molecular Sciences 14 30-45. (https://doi.org/10.3390/ijms14010030)

Chan DL, Segelov E \& Singh S 2017 Everolimus in the management of metastatic neuroendocrine tumours. Therapeutic Advances in Gastroenterology 10 132-141. (https://doi.org/10.1177/17562 83X16674660)

Chandarlapaty S, Sawai A, Scaltriti M, Rodrik-Outmezguine V, GrbovicHuezo O, Serra V, Majumder PK, Baselga J \& Rosen N 2011 AKT inhibition relieves feedback suppression of receptor tyrosine kinase expression and activity. Cancer Cell 19 58-71. (https://doi. org/10.1016/j.ccr.2010.10.031)

Chen BK, Ohtsuki Y, Furihata M, Takeuchi T, Iwata J, Liang SB \& Sonobe H 1999 Overexpression of c-Met protein in human thyroid tumors correlated with lymph node metastasis and clinicopathologic stage. Pathology: Research and Practice 195 427-433. (https://doi. org/10.1016/S0344-0338(99)80017-X)

Choi HS, Jeong EH, Lee TG, Kim SY, Kim HR \& Kim CH 2013 Autophagy inhibition with monensin enhances cell cycle arrest and apoptosis induced by mTOR or epidermal growth factor receptor inhibitors in lung cancer cells. Tuberculosis and Respiratory Diseases 75 9-17. (https://doi.org/10.4046/trd.2013.75.1.9)

Cohen P \& Frame S 2001 The renaissance of GSK3. Nature Reviews Molecular Cell Biology 2 769-776. (https://doi.org/10.1038/35096075)

De Buck SS, Jakab A, Boehm M, Bootle D, Juric D, Quadt C \& Goggin TK 2014 Population pharmacokinetics and pharmacodynamics of BYL719, a phosphoinositide 3-kinase antagonist, in adult patients with advanced solid malignancies. British Journal of Clinical Pharmacology 78 543-555. (https://doi.org/10.1111/bcp.12378)

Di Renzo MF, Olivero M, Ferro S, Prat M, Bongarzone I, Pilotti S, Belfiore A, Costantino A, Vigneri R, Pierotti MA, et al. 1992 Overexpression of the c-MET/HGF receptor gene in human thyroid carcinomas. Oncogene 7 2549-2553.

Domoto T, Pyko IV, Furuta T, Miyashita K, Uehara M, Shimasaki T, Nakada M \& Minamoto T 2016 Glycogen synthase kinase-3beta is a pivotal mediator of cancer invasion and resistance to therapy. Cancer Science 107 1363-1372. (https://doi.org/10.1111/cas.13028)

Ekeblad S, Skogseid B, Dunder K, Oberg K \& Eriksson B 2008 Prognostic factors and survival in 324 patients with pancreatic endocrine tumor treated at a single institution. Clinical Cancer Research 14 7798-7803. (https://doi.org/10.1158/1078-0432.CCR-08-0734)

Engelman JA, Zejnullahu K, Mitsudomi T, Song Y, Hyland C, Park JO, Lindeman N, Gale CM, Zhao X, Christensen J, et al. 2007 MET amplification leads to gefitinib resistance in lung cancer by 
activating ERBB3 signaling. Science 316 1039-1043. (https://doi. org/10.1126/science.1141478)

Evers BM, Townsend CM Jr, Upp JR, Allen E, Hurlbut SC, Kim SW, Rajaraman S, Singh P, Reubi JC \& Thompson JC 1991 Establishment and characterization of a human carcinoid in nude mice and effect of various agents on tumor growth. Gastroenterology 101 303-311. (https://doi.org/10.1016/0016-5085(91)90004-5)

Frilling A, Modlin IM, Kidd M, Russell C, Breitenstein S, Salem R, Kwekkeboom D, Lau WY, Klersy C, Vilgrain V, et al. 2014 Recommendations for management of patients with neuroendocrine liver metastases. Lancet Oncology 15 e8-e21. (https://doi.org/10.1016/ S1470-2045(13)70362-0)

Giancotti FG 2014 Deregulation of cell signaling in cancer. FEBS Letters 588 2558-2570. (https://doi.org/10.1016/j.febslet.2014.02.005)

Greenblatt DY, Ndiaye M, Chen H \& Kunnimalaiyaan M 2010 Lithium inhibits carcinoid cell growth in vitro. American Journal of Translational Research 2 248-253.

Grozinsky-Glasberg S, Shimon I \& Rubinfeld H 2012 The role of cell lines in the study of neuroendocrine tumors. Neuroendocrinology 96 173-187. (https://doi.org/10.1159/000338793)

Halfdanarson TR, Rabe KG, Rubin J \& Petersen GM 2008 Pancreatic neuroendocrine tumors (PNETs): incidence, prognosis and recent trend toward improved survival. Annals of Oncology 19 1727-1733. (https://doi.org/10.1093/annonc/mdn351)

He K, Chen D, Ruan H, Li X, Tong J, Xu X, Zhang L \& Yu J 2016 BRAFV600E-dependent Mcl-1 stabilization leads to everolimus resistance in colon cancer cells. Oncotarget 7 47699-47710. (https:// doi.org/10.18632/oncotarget.10277)

Juengel E, Makarevic J, Reiter M, Mani J, Tsaur I, Bartsch G, Haferkamp A \& Blaheta RA 2014 Resistance to the mTOR inhibitor temsirolimus alters adhesion and migration behavior of renal cell carcinoma cells through an integrin alpha5- and integrin beta3dependent mechanism. Neoplasia 16 291-300. (https://doi. org/10.1016/j.neo.2014.03.011)

Li Y, Kong D, Bao B, Ahmad A \& Sarkar FH 2011 Induction of cancer cell death by isoflavone: the role of multiple signaling pathways. Nutrients 3 877-896. (https://doi.org/10.3390/nu3100877)

Liao X, Sluimer JC, Wang Y, Subramanian M, Brown K, Pattison JS, Robbins J, Martinez J \& Tabas I 2012 Macrophage autophagy plays a protective role in advanced atherosclerosis. Cell Metabolism 15 545-553. (https://doi.org/10.1016/j.cmet.2012.01.022)

Liu Q, Shi X, Zhou X, Wang D, Wang L \& Li C 2014 Effect of autophagy inhibition on cell viability and cell cycle progression in MDAMB231 human breast cancer cells. Molecular Medicine Reports 10 625-630. (https://doi.org/10.3892/mmr.2014.2296)

Lubner SJ, Kunnimalaiyaan M, Holen KD, Ning L, Ndiaye M, Loconte NK, Mulkerin DL, Schelman WR \& Chen H 2011 A preclinical and clinical study of lithium in low-grade neuroendocrine tumors. Oncologist 16 452-457. (https://doi.org/10.1634/ theoncologist.2010-0323)

Ma PC, Kijima T, Maulik G, Fox EA, Sattler M, Griffin JD, Johnson BE \& Salgia R 2003 c-MET mutational analysis in small cell lung cancer: novel juxtamembrane domain mutations regulating cytoskeletal functions. Cancer Research 63 6272-6281.

Martelli AM, Buontempo F \& Evangelisti C 2014 GSK-3beta: a key regulator of breast cancer drug resistance. Cell Cycle 13 697-698. (https://doi.org/10.4161/cc.28091)

Marusyk A, Tabassum DP, Altrock PM, Almendro V, Michor F \& Polyak K 2014 Non-cell-autonomous driving of tumour growth supports subclonal heterogeneity. Nature 514 54-58. (https://doi.org/10.1038/ nature13556)

Maurer U, Preiss F, Brauns-Schubert P, Schlicher L \& Charvet C 2014 GSK-3 - at the crossroads of cell death and survival. Journal of Cell Science 127 1369-1378. (https://doi.org/10.1242/jcs.138057)

McCubrey JA, Steelman LS, Bertrand FE, Davis NM, Sokolosky M, Abrams SL, Montalto G, D'Assoro AB, Libra M, Nicoletti F, et al. 2014
GSK-3 as potential target for therapeutic intervention in cancer. Oncotarget 5 2881-2911. (https://doi.org/10.18632/oncotarget.2037)

McCubrey JA, Rakus D, Gizak A, Steelman LS, Abrams SL, Lertpiriyapong K, Fitzgerald TL, Yang LV, Montalto G, Cervello M, et al. 2016 Effects of mutations in Wnt/beta-catenin, hedgehog, Notch and PI3K pathways on GSK-3 activity-Diverse effects on cell growth, metabolism and cancer. Biochimica et Biophysica Acta 1863 2942-2976. (https://doi.org/10.1016/j.bbamcr.2016.09.004)

McDermott M, Eustace AJ, Busschots S, Breen L, Crown J, Clynes M, O'Donovan N \& Stordal B 2014 In vitro development of chemotherapy and targeted therapy drug-resistant cancer cell lines: a practical guide with case studies. Frontiers in Oncology 4 40. (https:// doi.org/10.3389/fonc.2014.00040)

Mejias-Pena Y, Estebanez B, Rodriguez-Miguelez P, Fernandez-Gonzalo R, Almar M, de Paz JA, Gonzalez-Gallego J \& Cuevas MJ 2017 Impact of resistance training on the autophagy-inflammation-apoptosis crosstalk in elderly subjects. Aging 9 408-418. (https://doi. org/10.18632/aging.101167)

Mussmann R, Geese M, Harder F, Kegel S, Andag U, Lomow A, Burk U, Onichtchouk D, Dohrmann C \& Austen M 2007 Inhibition of GSK3 promotes replication and survival of pancreatic beta cells. Journal of Biological Chemistry 282 12030-12037. (https://doi.org/10.1074/jbc. M609637200)

Nölting S, Rentsch J, Freitag H, Detjen K, Briest F, Mobs M, Weissmann V, Siegmund B, Auernhammer CJ, Aristizabal Prada ET, et al. 2017 The selective PI3Kalpha inhibitor BYL719 as a novel therapeutic option for neuroendocrine tumors: Results from multiple cell line models. PLoS ONE 12 e0182852. (https://doi.org/10.1371/ journal.pone.0182852)

Nurse P 1990 Universal control mechanism regulating onset of M-phase. Nature 344 503-508. (https://doi.org/10.1038/344503a0)

O'Reilly KE, Rojo F, She QB, Solit D, Mills GB, Smith D, Lane H, Hofmann F, Hicklin DJ, Ludwig DL, et al. 2006 mTOR inhibition induces upstream receptor tyrosine kinase signaling and activates Akt. Cancer Research 66 1500-1508. (https://doi.org/10.1158/00085472.CAN-05-2925)

Passacantilli I, Capurso G, Archibugi L, Calabretta S, Caldarola S, Loreni F, Delle Fave G \& Sette C 2014 Combined therapy with RAD001 e BEZ235 overcomes resistance of PET immortalized cell lines to mTOR inhibition. Oncotarget 5 5381-5391. (https://doi. org/10.18632/oncotarget.2111)

Pavel ME \& Sers C 2016 WOMEN IN CANCER THEMATIC REVIEW: Systemic therapies in neuroendocrine tumors and novel approaches toward personalized medicine. Endocrine-Related Cancer $\mathbf{2 3}$ T135-T154. (https://doi.org/10.1530/ERC-16-0370)

Pavel ME, Hainsworth JD, Baudin E, Peeters M, Horsch D, Winkler RE, Klimovsky J, Lebwohl D, Jehl V, Wolin EM, et al. 2011 Everolimus plus octreotide long-acting repeatable for the treatment of advanced neuroendocrine tumours associated with carcinoid syndrome (RADIANT-2): a randomised, placebo-controlled, phase 3 study. Lancet 378 2005-2012. (https://doi.org/10.1016/S01406736(11)61742-X)

Pirola L, Bonnafous S, Johnston AM, Chaussade C, Portis F \& Van Obberghen E 2003 Phosphoinositide 3-kinase-mediated reduction of insulin receptor substrate-1/2 protein expression via different mechanisms contributes to the insulin-induced desensitization of its signaling pathways in L6 muscle cells. Journal of Biological Chemistry 278 15641-15651. (https://doi.org/10.1074/jbc. M208984200)

Porta C, Paglino C \& Mosca A 2014 Targeting PI3K/Akt/mTOR signaling in cancer. Frontiers in Oncology 4 64. (https://doi.org/10.3389/ fonc.2014.00064)

Potapova TA, Daum JR, Byrd KS \& Gorbsky GJ 2009 Fine tuning the cell cycle: activation of the Cdk1 inhibitory phosphorylation pathway during mitotic exit. Molecular Biology of the Cell 20 1737-1748. (https://doi.org/10.1091/mbc.e08-07-0771) (c) 2018 Society for Endocrinology Published by Bioscientifica Ltd. Printed in Great Britain 
Reuther C, Heinzle V, Spampatti M, Vlotides G, de Toni E, Spottl G, Maurer J, Nolting S, Goke B \& Auernhammer CJ 2016 Cabozantinib and tivantinib, but not INC280, induce antiproliferative and antimigratory effects in human neuroendocrine tumor cells in vitro: evidence for 'off-target' effects not mediated by c-Met inhibition. Neuroendocrinology 103 383-401. (https://doi. org/10.1159/000439431)

Riccardi C \& Nicoletti I 2006 Analysis of apoptosis by propidium iodide staining and flow cytometry. Nature Protocols 1 1458-1461. (https:// doi.org/10.1038/nprot.2006.238)

Shimura T 2011 Acquired radioresistance of cancer and the AKT/ GSK3beta/cyclin D1 overexpression cycle. Journal of Radiation Research 52 539-544. (https://doi.org/10.1269/jrr.11098)

Shipkova M, Hesselink DA, Holt DW, Billaud EM, van Gelder T, Kunicki PK, Brunet M, Budde K, Barten MJ, De Simone P, et al. 2016 Therapeutic drug monitoring of everolimus: a consensus report. Therapeutic Drug Monitoring 38 143-169. (https://doi.org/10.1097/ FTD.0000000000000260)

Soares KC, Foley K, Olino K, Leubner A, Mayo SC, Jain A, Jaffee E, Schulick RD, Yoshimura K, Edil B, et al. 2014 A preclinical murine model of hepatic metastases. Journal of Visualized Experiments 51677. (https://doi.org/10.3791/51677)

Song J, Li M, Tretiakova M, Salgia R, Cagle PT \& Husain AN 2010 Expression patterns of PAX5, c-Met, and paxillin in neuroendocrine tumors of the lung. Archives of Pathology and Laboratory Medicine $\mathbf{1 3 4}$ 1702-1705. (https://doi.org/10.1043/2009-0664-OAR1.1)

Sui X, Chen R, Wang Z, Huang Z, Kong N, Zhang M, Han W, Lou F, Yang J, Zhang Q, et al. 2013 Autophagy and chemotherapy resistance: a promising therapeutic target for cancer treatment. Cell Death and Disease 4 e838. (https://doi.org/10.1038/cddis.2013.350)

Takeo S, Arai H, Kusano N, Harada T, Furuya T, Kawauchi S, Oga A, Hirano T, Yoshida T, Okita K, et al. 2001 Examination of oncogene amplification by genomic DNA microarray in hepatocellular carcinomas: comparison with comparative genomic hybridization analysis. Cancer Genetics and Cytogenetics 130 127-132. (https://doi. org/10.1016/S0165-4608(01)00479-4)

Vandamme T, Beyens M, de Beeck KO, Dogan F, van Koetsveld PM, Pauwels P, Mortier G, Vangestel C, de Herder W, Van Camp G, et al. 2016 Long-term acquired everolimus resistance in pancreatic neuroendocrine tumours can be overcome with novel PI3K-AKTmTOR inhibitors. British Journal of Cancer 114 650-658. (https://doi. org/10.1038/bjc.2016.25)

Wada A 2009 GSK-3 inhibitors and insulin receptor signaling in health, disease, and therapeutics. Frontiers in Bioscience 14 1558-1570. (https://doi.org/10.2741/3324)

Wagle N, Grabiner BC, Van Allen EM, Amin-Mansour A, TaylorWeiner A, Rosenberg M, Gray N, Barletta JA, Guo Y, Swanson SJ, et al. 2014 Response and acquired resistance to everolimus in anaplastic thyroid cancer. New England Journal of Medicine 371 1426-1433. (https://doi.org/10.1056/NEJMoa1403352)

Weikel KA, Cacicedo JM, Ruderman NB \& Ido Y 2016 Knockdown of GSK3beta increases basal autophagy and AMPK signalling in nutrient-laden human aortic endothelial cells. Bioscience Reports 36 e00382. (https://doi.org/10.1042/BSR20160174)

Wolin EM 2013 PI3K/Akt/mTOR pathway inhibitors in the therapy of pancreatic neuroendocrine tumors. Cancer Letters 335 1-8. (https:// doi.org/10.1016/j.canlet.2013.02.016)

Yao JC, Hassan M, Phan A, Dagohoy C, Leary C, Mares JE, Abdalla EK, Fleming JB, Vauthey JN, Rashid A, et al. 2008 One hundred years after 'carcinoid': epidemiology of and prognostic factors for neuroendocrine tumors in 35,825 cases in the United States. Journal of Clinical Oncology 26 3063-3072. (https://doi.org/10.1200/ JCO.2007.15.4377)

Yao JC, Shah MH, Ito T, Bohas CL, Wolin EM, Van Cutsem E, Hobday TJ, Okusaka T, Capdevila J, de Vries EG, et al. 2011 Everolimus for advanced pancreatic neuroendocrine tumors. New England Journal of Medicine 364 514-523. (https://doi.org/10.1056/ NEJMoa1009290)

Yao JC, Phan AT, Jehl V, Shah G \& Meric-Bernstam F 2013 Everolimus in advanced pancreatic neuroendocrine tumors: the clinical experience. Cancer Research 73 1449-1453. (https://doi.org/10.1158/0008-5472. CAN-12-3923)

Yao J, Wang JY, Liu Y, Wang B, Li YX, Zhang R, Wang LS \& Liu L 2014 A randomized phase II study of everolimus for advanced pancreatic neuroendocrine tumors in Chinese patients. Medical Oncology 31 251. (https://doi.org/10.1007/s12032-014-0251-x)

Yao JC, Fazio N, Singh S, Buzzoni R, Carnaghi C, Wolin E, Tomasek J, Raderer M, Lahner H, Voi M, et al. $2016 a$ Everolimus for the treatment of advanced, non-functional neuroendocrine tumours of the lung or gastrointestinal tract (RADIANT-4): a randomised, placebo-controlled, phase 3 study. Lancet 387 968-977. (https://doi. org/10.1016/S0140-6736(15)00817-X)

Yao JC, Pavel M, Lombard-Bohas C, Van Cutsem E, Voi M, Brandt U, He W, Chen D, Capdevila J, de Vries EG, et al. 2016b Everolimus for the treatment of advanced pancreatic neuroendocrine tumors: overall survival and circulating biomarkers from the randomized, phase III RADIANT-3 study. Journal of Clinical Oncology $\mathbf{3 4}$ 3906-3913. (https://doi.org/10.1200/JCO.2016.68.0702)

Zatelli MC, Fanciulli G, Malandrino P, Ramundo V, Faggiano A, Colao A \& Group N 2016 Predictive factors of response to mTOR inhibitors in neuroendocrine tumours. Endocrine-Related Cancer 23 R173-R183. (https://doi.org/10.1530/ERC-15-0413)

Zaytseva YY, Valentino JD, Gulhati P \& Evers BM 2012 mTOR inhibitors in cancer therapy. Cancer Letters 319 1-7. (https://doi.org/10.1016/j. canlet.2012.01.005)

Zhang C, Hou B, Yu S, Chen Q, Zhang N \& Li H 2016 HGF alleviates high glucose-induced injury in podocytes by GSK3beta inhibition and autophagy restoration. Biochimica et Biophysica Acta 1863 2690-2699. (https://doi.org/10.1016/j.bbamcr.2016.08.004)

Zitzmann K, Ruden J, Brand S, Goke B, Lichtl J, Spottl G \& Auernhammer CJ 2010 Compensatory activation of Akt in response to mTOR and Raf inhibitors - a rationale for dual-targeted therapy approaches in neuroendocrine tumor disease. Cancer Letters 295 100-109. (https://doi.org/10.1016/j.canlet.2010.02.018)

Received in final form 7 June 2018

Accepted 11 June 2018

Accepted Preprint published online 12 June 2018 (c) 2018 Society for Endocrinology Published by Bioscientifica Ltd. Printed in Great Britain 